\title{
Correction to: Contour analysis for interpretable leaf shape category discovery
}

Jorge Victorino ${ }^{1,2}$ and Francisco Gómez $z^{3^{*}}$

\section{Correction to: Plant Methods (2019) 15:112} https://doi.org/10.1186/s13007-019-0497-6

Unfortunately, the original version of the article [1] contained an error in Figure 7. The names of species Ulmus minor and Acer campestre were interchanged. The corrected Fig. 7 is given here. 


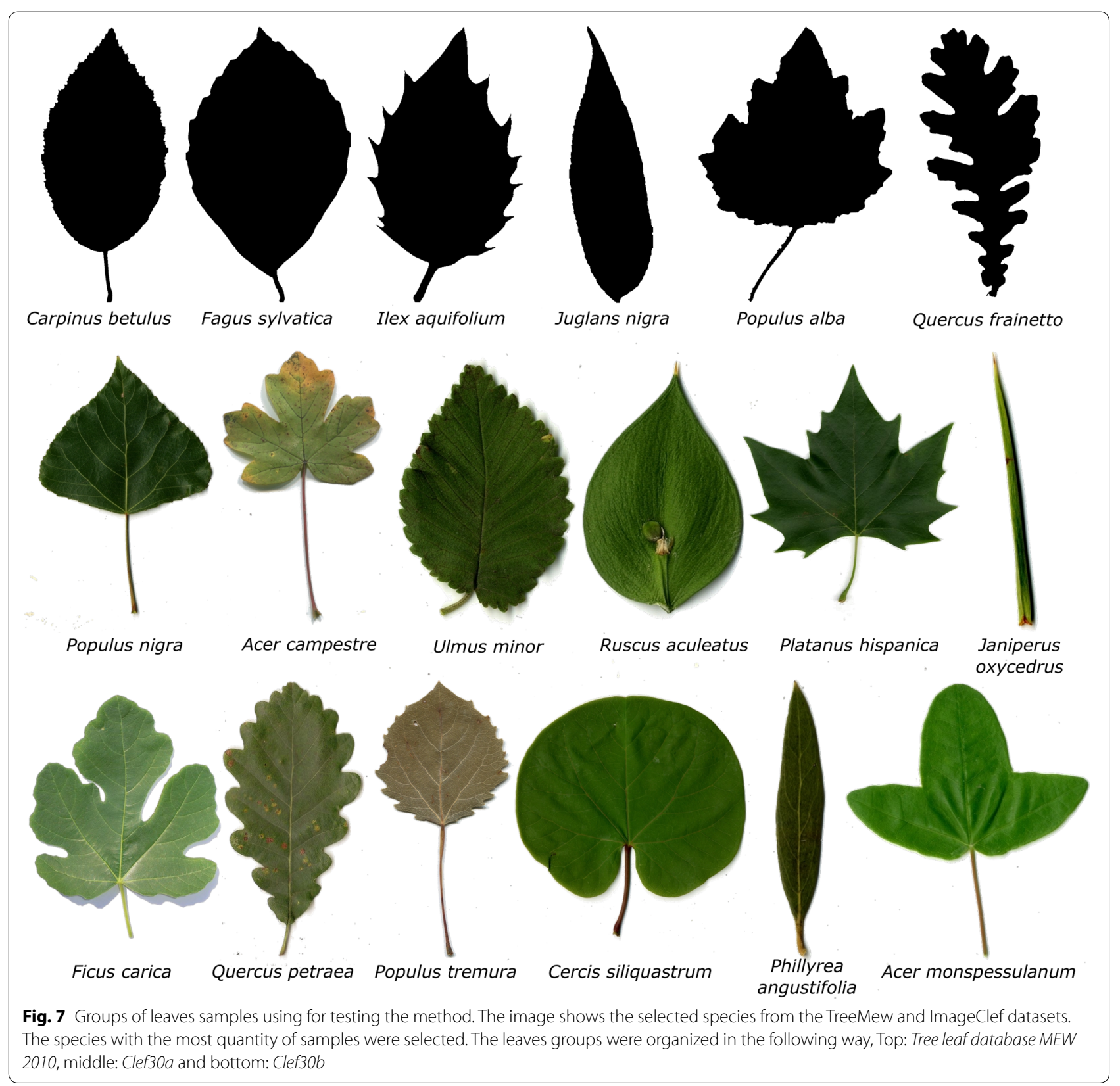

\section{Author details}

${ }^{1}$ Departament of System Engineering, Universidad Central, Bogotá 110311, Colombia. ${ }^{2}$ Department of System Engineering, Universidad Nacional, Bogotá 111311, Colombia. ${ }^{3}$ Departamento de matemáticas, Universidad Nacional de Colombia, Bogotá 111311, Colombia.

Published online: 16 November 2019

\section{Publisher's Note}

Springer Nature remains neutral with regard to jurisdictional claims in published maps and institutional affiliations.

\section{Reference}

1. Victorino J, Gómez F. Contour analysis for interpretable leaf shape category discovery. Plant Methods. 2019;15(1):112. https://doi.org/10.1186/ s13007-019-0497-6 